\title{
The use of IASI data to identify systematic errors in the ECMWF forecasts of temperature in the upper stratosphere
}

\author{
G. Masiello ${ }^{1}$, M. Matricardi ${ }^{2}$, and C. Serio ${ }^{1}$ \\ ${ }^{1}$ DIFA, University of Basilicata, Potenza, Italy \\ ${ }^{2}$ ECMWF, Shinfield Park, Reading, UK
}

Received: 21 June 2010 - Published in Atmos. Chem. Phys. Discuss.: 5 October 2010

Revised: 25 January 2011 - Accepted: 26 January 2011 - Published: 4 February 2011

\begin{abstract}
Since data from the Infrared Atmospheric Sounding Interferometer (IASI) became available in 2007, a number of papers have appeared in the literature which have reported relatively large discrepancies between IASI spectra and forward calculations in the centre of the $\mathrm{CO}_{2}$ Q-branch at $667 \mathrm{~cm}^{-1}$. In this paper we show that these discrepancies are primarily due to errors in the temperature profiles used in the forward calculations. In particular, we have used forecasts of temperature profiles from the European Centre for MediumRange Weather Forecasts (ECMWF) to demonstrate that, for the case study considered in this paper, these profiles are affected by systematic errors of the order of $\approx 10 \mathrm{~K}$ at the level of the stratopause. To derive the magnitude and the spatial location of the systematic errors in the temperature profile, we have carried out forward/inverse calculations for a number of clear-sky, daytime, IASI tropical soundings over the sea. The forward calculations have been performed using atmospheric state vectors which have been obtained either from the direct inversion of the IASI radiances or from space-time co-located profiles derived from radiosonde observations and from the ECMWF model. To rule out any effect due to the accuracy of the forward model, we have performed the forward calculations using two independent models. The sensitivity of the temperature biases to the variability of the $\mathrm{CO}_{2}$ profile and to spectroscopy errors has also been studied.
\end{abstract}

\section{Introduction}

The Infrared Atmospheric Sounding Interferometer (IASI) is providing data of unprecedented spectral resolution and accuracy for an operational infrared sounding instrument (see e.g. the recent IASI special issue edited by Richter and Wag-

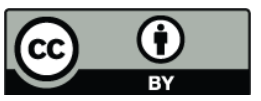

Correspondence to: M. Matricardi (marco.matricardi@ecmwf.int) ner (2009)). The assimilation of IASI radiances has produced a significant positive impact on forecast quality (e.g. Collard and McNally (2009)) and on the exploitation of trace gas information for atmospheric chemistry.

IASI has been developed in France by the Centre National d'Etudes Spatiales (CNES) and is flying on board the MetopA (Meteorological Operational Satellite) platform, the first of three satellites of the European Organization for the Exploitation of Meteorological Satellites (EUMETSAT) European Polar System (EPS).

Since the very early stages of the IASI data usage, the scientific community has observed a large discrepancy between IASI spectra and radiative transfer calculations (see, e.g., Fig. 1) at the centre of the $\mathrm{CO}_{2}$ fundamental Q-branch at $667 \mathrm{~cm}^{-1}(15 \mu \mathrm{m})$. This result has been documented in a number of unpublished presentations made during the second workshop of the EUMETSAT IASI Sounding Science Working Group (ISSWG-2) and in several papers published in the open literature, e.g. see Shephard et al. (2009); Matricardi (2009); Masiello et al. (2009).

In general, but especially in the spectral range around $667 \mathrm{~cm}^{-1}$, the IASI datasets are of much improved quality and accuracy when compared to those from earlier spaceborne Fourier transform spectrometers operating in nadir looking mode, as shown, e.g. in Fig. 2. The high spectral stability and the absolute radiometric accuracy of the IASI instrument (e.g. see Strow et al. (2008) and Illingworth et al. (2009)) rules out the possibility that the large residuals discussed above are attributable to the instrument itself. In fact, as shown in Fig. 3, we found that large discrepancies between observations and simulations are also observed in the spectra of the Atmospheric Infrared Sounder (AIRS) instrument. In this case simulations were performed using the RTTOV (Matricardi et al. (2004)) forward model and input fields obtained from the ECMWF short-range forecasts.

Shephard et al. (2009) and Matricardi (2009) have suggested that the radiance bias at $667 \mathrm{~cm}^{-1}$ could be caused by

Published by Copernicus Publications on behalf of the European Geosciences Union. 


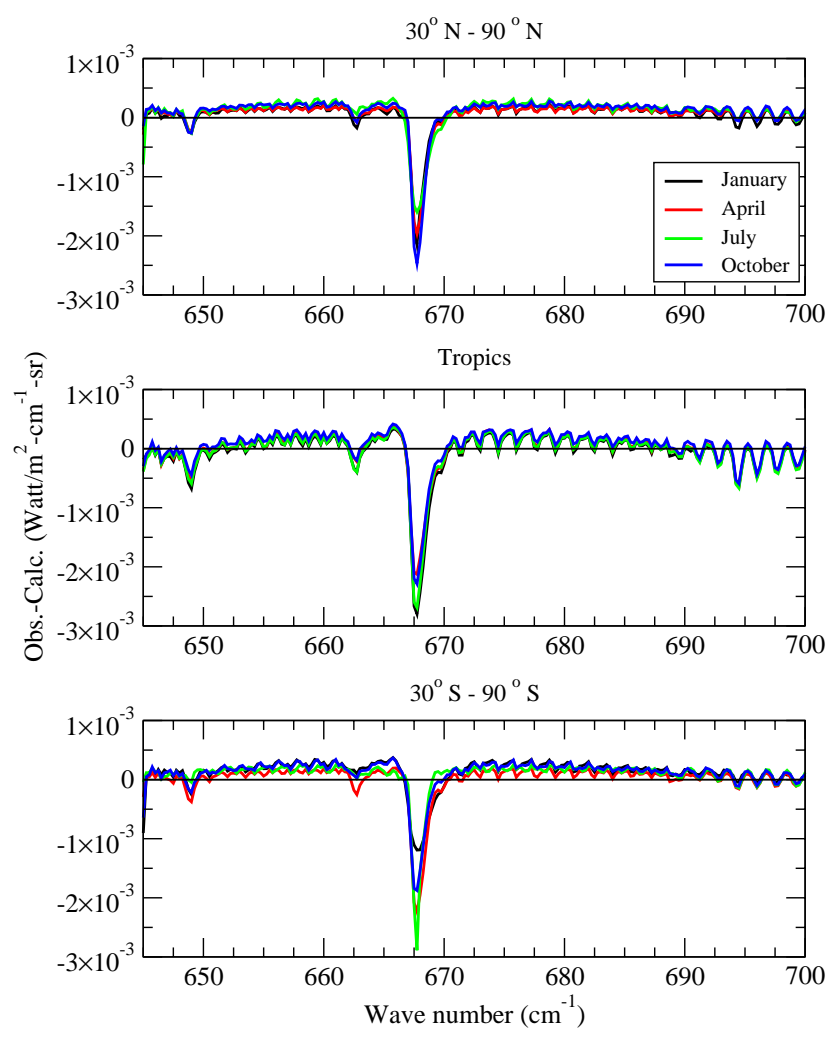

Fig. 1. IASI spectral residuals averaged over a period of two weeks during January, April, July, and, October 2008. The input state vectors are ECMWF short-range forecast fields. The residuals have been computed using the RTTOV model. Results are shown for (a) Northern Hemisphere, (b) Tropics, and, (c) Southern Hemisphere.

incorrect specification of the temperature profile in the upper stratosphere. Masiello et al. (2009) have provided further evidence connecting directly the radiance bias to errors in the temperature profile.

In the present paper we elaborate further on the results obtained by the above mentioned authors and give an explicit assessment of the radiance bias at $667 \mathrm{~cm}^{-1}$ in terms of systematic errors in the temperature profiles. Specifically, we discuss errors in the ECMWF temperature.

Several studies (e.g., see Fischer et al. (2008) and references therein), suggest that roto-vibrational $\mathrm{CO}_{2}$ lines could be affected by variations of the $\mathrm{CO}_{2}$ volume mixing ratio in the mesosphere and lower thermosphere and by non Local Thermodynamic Equilibrium (LTE) effects. These effects, if not properly accounted for, could result in large differences between observed and calculated spectra.

As far as non-LTE effects are concerned, the main reasons why they cannot be responsible for the observed bias at $667 \mathrm{~cm}^{-1}$ is that biases are observed during nightime and daytime whereas, to a large degree, non LTE effects should only affect daytime radiances. It should also be observed that IASI is a nadir looking instrument and therefore it has poor

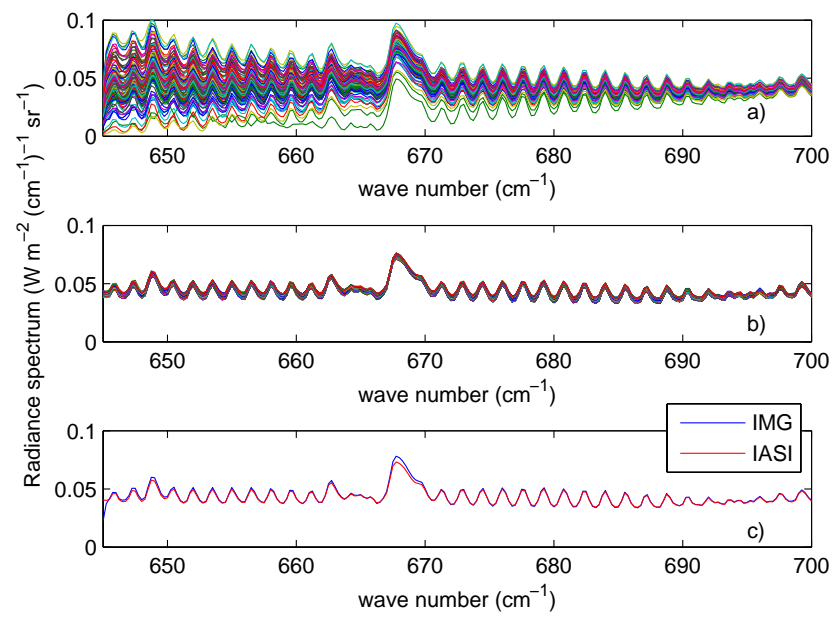

Fig. 2. This figure illustrates how much more accurate the IASI spectra in the long wave $\mathrm{CO}_{2}$ absorption band are in comparison with those measured by an equivalent, albeit ten years older, instrument, namely the Japanese IMG (Interferometric Monitoring of Greenhouse Gases, Kobayashi et al. (1999)). The comparison focuses on the range 645 to $700 \mathrm{~cm}^{-1}$. Panel (a) shows a set of sea-surface IMG spectra (see Masiello et al. (2003)) recorded in the tropics; panel (b) shows an equivalent set of IASI spectra also recorded in the tropics; the panel (c) shows the averaged value of the spectra shown in panel (a) and (b), respectively. The good agreement between the mean values shown in panel (c) means that the variability seen in panel (a) is just random.

sensitivity to emission above the stratopause. Moreover, nonLTE effects in the $\mathrm{CO}_{2} \nu_{2}$ band, which covers approximately the range from 550 to $800 \mathrm{~cm}^{-1}$, are only important above $80 \mathrm{~km}$.

Regarding the issue of the variation of the $\mathrm{CO}_{2}$ mixing ratio with altitude, we have explicitly assumed that $\mathrm{CO}_{2}$ is not well mixed. To this end we have used ECMWF $\mathrm{CO}_{2}$ profiles obtained from the assimilation of the Atmospheric Infrared Sounder (AIRS) (Engelen et al. (2009)) radiances. Since we expect the $\mathrm{CO}_{2}$ profiles to be affected by temperature errors in the ECMWF model, we have carried out a comparison with a case of constant mixing ratio to check the sensitivity of the retrieval to the $\mathrm{CO}_{2}$ profile.

The origin of the radiance bias could in principle be related to line-shape issues such as the effect of line-mixing. However, in that respect, it should be noted that, as shown by, e.g., Strow and Reuter (1988); Niro et al. (2004, 2005a,b), Qbranches within the $v_{2} \mathrm{CO}_{2}$ absorption band, are well modeled. Random errors of line parameters (width and intensity) would be almost zeroed after convolution with the IASI Instrument Spectral Response Function. To sum up, to our knowledge, there is no evidence that spectroscopic data are affected by biases of a magnitude as large as to yield the bias we observe at $667 \mathrm{~cm}^{-1}$.

It should be said, however, that in our forward calculations, the treatment of the $\mathrm{CO}_{2}$ absorption is made in terms 

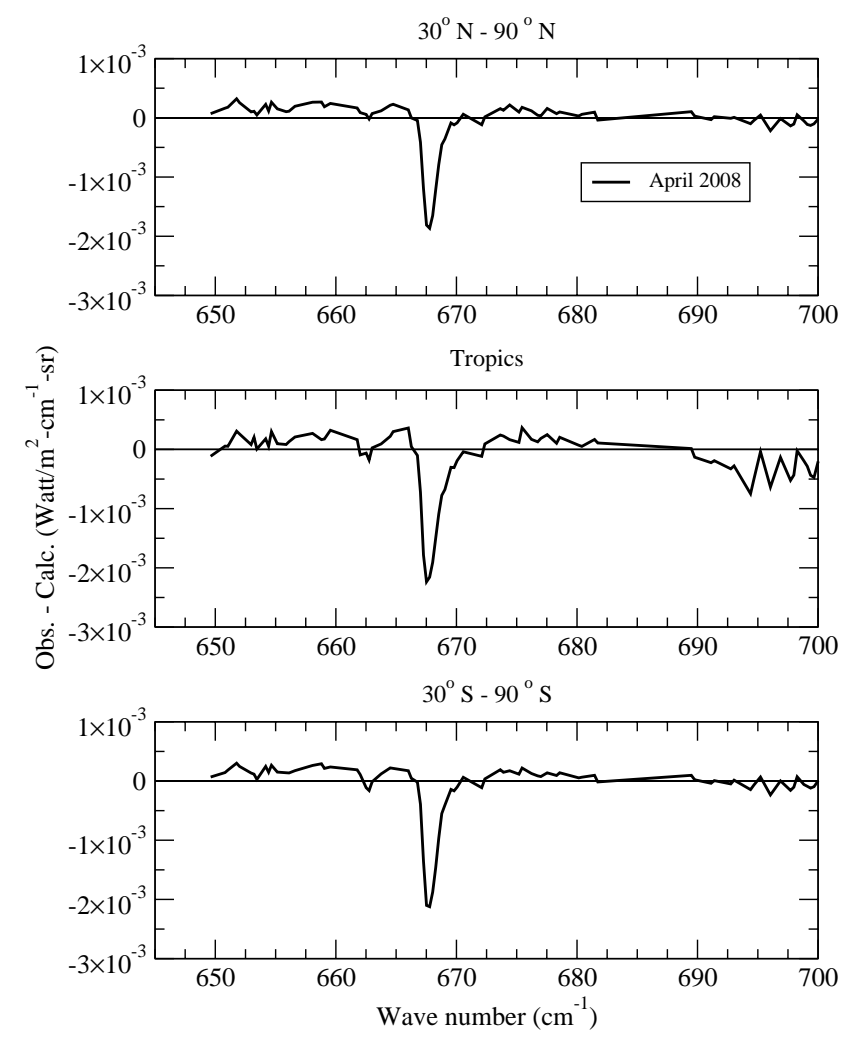

Fig. 3. AIRS spectral residuals averaged over a period of two weeks during April 2008. The input state vectors are ECMWF short-range forecast fields. The residuals have been computed using the RTTOV model. Results are shown for (a) Northern Hemisphere, (b) Tropics, and, (c) Southern Hemisphere.

of line and continuum components. The continuum absorption at the centre of the $\mathrm{CO}_{2} \nu_{2}$ band displays a behaviour very similar to that displayed by the radiance bias (i.e. a very narrow and sharp structure). For this reason, we have studied the sensitivity of our results to the perturbation of the continuum absorption.

A recent validation study (von Engeln et al., 2009) performed using data from the radio occultation (RO) GNSS (Global Navigation Satellite System) Receiver for Atmospheric Sounding (GRAS) instrument, shows biases in the ECMWF temperature profiles in the stratosphere which are qualitatively consistent with the biases discussed in this paper. Since GRAS data are not reliable below pressures of $5 \mathrm{hPa}$, it is not possible to use these data to corroborate our findings in the pressure altitude range between 5 and $0.1 \mathrm{hPa}$ where we found the ECMWF temperature biases are most pronounced.

Given the difficulty (if not the impossibility) of a direct validation of the ECMWF forecasts of temperature in the upper stratosphere, we can gain some insight into the behaviour of the ECMWF temperature fields in this region by using the stratospheric/mesospheric temperature sounding channels of the Special Sensor Microwave Imager/Sounder (SSMI/S) instrument. To this end, the statistics of the (largely negative) differences between observations and radiances simulated using profiles from the ECMWF forecasts, suggests the presence of an increasing ECMWF temperature bias between 45 and $85 \mathrm{~km}$ (B. Bell, personal communication, 2010). This finding is consistent with the results presented in this paper.

Further evidence that the ECMWF model temperature is biased at the stratopause level comes from the study of the MIPAS retrievals (Ridolfi et al., 2007). The analysis of the MIPAS data tends to agree with our findings in that they show that the ECMWF temperatures around $1 \mathrm{hPa}$ are higher than those retrieved by MIPAS. The bias shows the same sign and is comparable in magnitude with the bias we have found using IASI data. It should be also stressed that MIPAS spectral coverage stops at $700 \mathrm{~cm}^{-1}$ and therefore provides also an independent evidence that the bias is not an artifact of the spectroscopy within the $667 \mathrm{~cm}^{-1}$ Q-branch.

It should be noted that the ECMWF analysis in the stratosphere is mainly driven by the assimilation of the Advanced Microwave Sounding Unit (AMSU) radiances. IASI (and AIRS) radiances in the center of the $667 \mathrm{~cm}^{-1}$ Q-branch are not currently assimilated.

Regarding the IASI datasets, based on the work by Matricardi (2009); Shephard et al. (2009); Masiello et al. (2009), it can be seen that biases at $667 \mathrm{~cm}^{-1}$ exhibit a very coherent pattern, i.e. a cold anomaly everywhere on the globe: IASI is colder than the ECMWF-forecasts-based radiative transfer calculations. It is important to stress how the biases at $667 \mathrm{~cm}^{-1}$ do not display any day-night cycle (see e.g. Matricardi (2009)). However, as exemplified in Fig. 1, it is evident that seasonal variations are present in the residuals. Figure 1 shows the residuals computed over a period of two weeks during the months of April, July, October, and, January 2008 using the experimental set up described in Matricardi (2009) (i.e. simulations have been performed using the RTTOV forward model and ECMWF short-range forecasts fields of temperature, water vapour and ozone). Variations can be larger if the residuals are computed locally.

In this paper we study the origin of the biases at $667 \mathrm{~cm}^{-1}$ using a few, geo-located, IASI spectra and good quality insitu information, which allow us to perform a consistent radiance closure experiment.

To this end, clear-sky, sea-surface, daytime IASI observations have been obtained from the Joint Airborne IASI Validation Experiment (JAIVEx) (FAAM, 2007), which was carried out in the United States during April and May 2007. The JAIVEx team has also complemented these IASI observations by a comprehensive ancillary data set to specify the state of the atmosphere corresponding to the MetOp overpasses.

In this paper, IASI simulations have been performed using two forward models, $\sigma$-IASI (Amato et al., 2002; Grieco et al., 2007; Masiello et al., 2009) and the newly developed principal component based version of the RTTOV fast 
radiative transfer model (Matricardi, 2010). The strategy of using two independent forward models allows us to determine whether or not there is any dependence of the bias on the forward model itself. The two forward models are based on different but recent versions of the LBLRTM line-byline (LBL) radiative transfer model (http://rtweb.aer.com/) (i.e. v.11.6 for $\sigma$-IASI and v.11.1 for RTTOV). It should be noted that, as discussed in Matricardi (2009), biases in the $667 \mathrm{~cm}^{-1}$ Q-branch are present in the residuals computed using a range of different LBL models. For instance, the residuals computed using the kCARTA (DeSouza-Machado et al. (2002)) LBL model exhibit biases that are typically of the order of $-1.2 \mathrm{~K}$. These findings are confirmed by recent results obtained by S. DeSouza-Machado (personal communication, 2010) which show that kCARTA direct calculations based on ECMWF state vectors, show a bias (observationscalculations) of -1 to $-2 \mathrm{~K}$ on average when compared to IASI observations.

For the inversion of the spectral radiances, we have utilized the $\delta$-IASI (Carissimo et al., 2005; Masiello and Serio, 2004; Serio et al., 2009) package, which has been used for the simultaneous inversion of skin temperature, temperature, water vapour and ozone profiles.

\section{Methodological background}

The quality of the retrievals of atmospheric parameters can be assessed by a proper analysis of the spectral residuals. Once we get the final estimate of the atmospheric state vector, we can compute the corresponding fitted spectrum, say $\hat{R}(\sigma)$, where $\sigma$ is the wave number, and compare it to the observed spectrum, $R(\sigma)$. If $F$ is the forward model function and $\hat{v}$ the estimated state vector, then the spectral residual is

$\delta R(\sigma)=R(\sigma)-\hat{R}(\sigma), \hat{R}(\sigma)=F(\hat{\boldsymbol{v}})$

If the spectrum is computed at $N$ different wave numbers, $\sigma_{j}$, with $j=1, \ldots, N$, then the spectral residual can be expressed as a vector of size $N$,

$\delta \mathbf{R}=\left(\delta R_{1}, \ldots, \delta R_{j}, \ldots, \delta R_{N}\right)^{\mathrm{t}}$

where the superscript $t$ indicates transposition and

$\delta R\left(\sigma_{j}\right)=\delta R_{j}$

The spectral residual can be computed for any individual sounding. Therefore we add an index $i$ to the residual vector, $\delta \mathbf{R}_{i}$, where $i$ can run over the set of $n$ available soundings.

\subsection{The two forward models}

The radiative transfer calculations used for the radiance inversion have been performed using the $\phi$-IASI package. This package incorporates a forward model, which we call $\sigma$ IASI, and a non-linear iterative inverse algorithm, which we
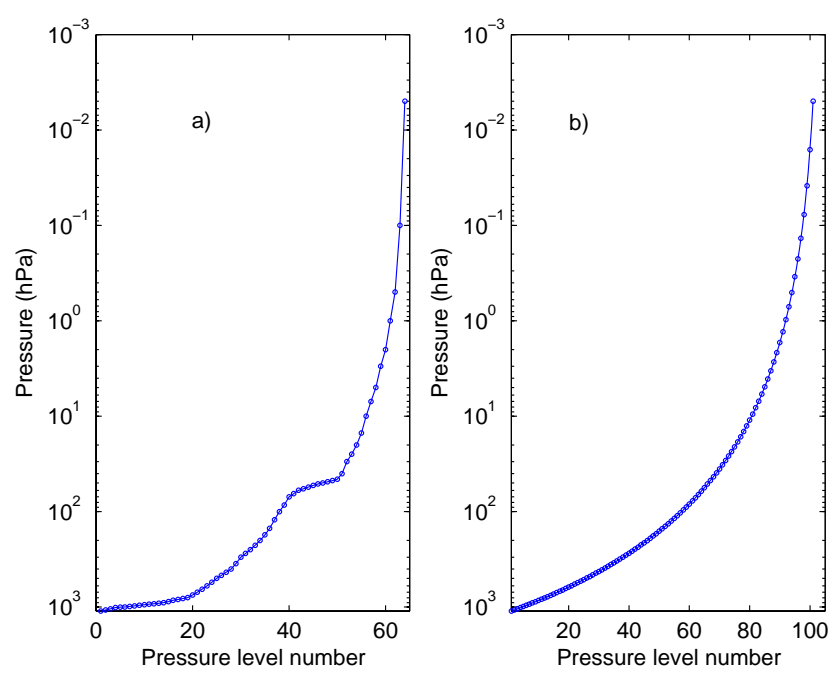

Fig. 4. The definition of the atmospheric pressure levels used in a) $\sigma$-IASI and b) RTTOV.

call $\delta$-IASI. In this way, we use a consistent method to perform a radiance closure experiment where a given first guess state vector is iteratively adjusted until convergence in the radiance space (i.e. the minimization of the spectral residuals) is reached.

The $\phi$-IASI scheme has been described in several papers (Amato et al., 2002; Grieco et al., 2007; Masiello et al., 2009; Carissimo et al., 2005; Masiello and Serio, 2004; Serio et al., 2009). The reader can refer to these papers for further details. Here we only describe those aspects which are relevant to the present analysis.

The $\sigma$-IASI module is a monochromatic radiative transfer model, which uses an appropriate atmospheric layering to model the optical depths. The layering consists of a grid of vertical layers of constant pressure. The discretized version of the radiative transfer equation, which is solved within $\sigma$-IASI, uses a 63-layer pressure grid which spans the range $1100-0.005 \mathrm{hPa}$. The 64 atmospheric pressure levels, which divide the atmosphere into 63 layers are shown in Fig. $4 a$. Note the relatively higher density of layers at pressure levels just above the tropopause. This is the standard configuration, which allows us to use the same model to simulate data recorded by instruments on board aircrafts flying at about $20 \mathrm{~km}$ altitude.

By using $\phi$-IASI we can check the consistency of the forward/inverse calculations. The state vector retrieved by $\phi$ IASI is then used as an input to RTTOV to check if the spectral residuals are consistent with those obtained using $\sigma$-IASI. The results can be used as an independent validation of the hypothesis that biases in the temperature profile are indeed responsible for the radiance biases at $667 \mathrm{~cm}^{-1}$.

Of course, we expect to see differences between the $\sigma$ IASI and RTTOV calculations due to the different radiative transfer schemes and, above all, to the different pressure grid 


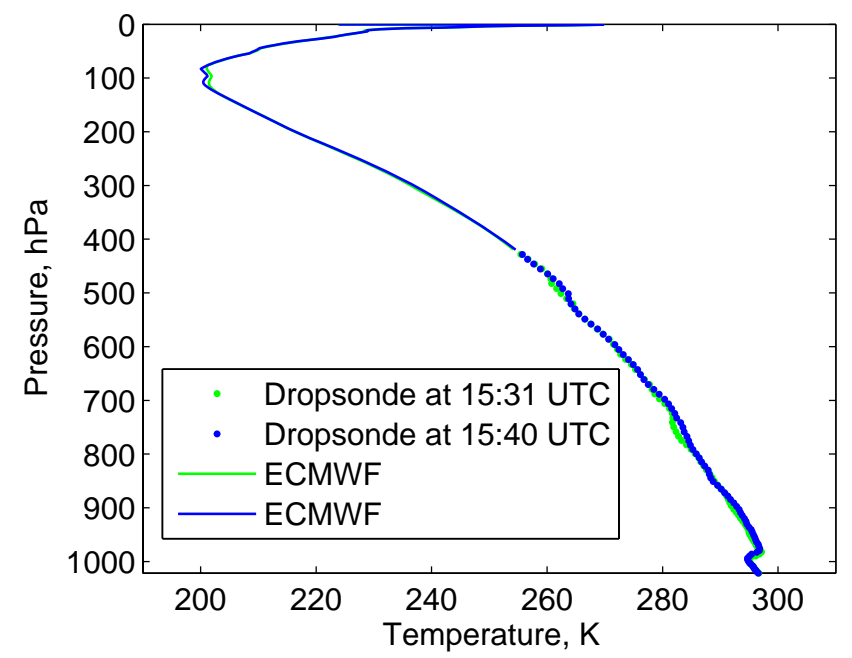

Fig. 5. JAIVEx case study, 29 April 2007. The figure shows the temperature profiles obtained from dropsonde data and the upper atmosphere ECMWF model data.

used to discretize the atmospheric state vector. In fact, RTTOV uses the 101_levels pressure grid specified by the AIRS science team. This is shown in Fig. 4b. In addition, the input to the $\sigma$-IASI model are layer mean temperatures, whereas RTTOV uses temperatures at the boundaries of each layer. This means that the $\phi$-IASI mean layer retrieved profiles have to be interpolated to grid point values and this process can introduce differences in the atmospheric state vector. These differences tend to increase in the upper atmosphere where both grids become coarser (see Fig. 4).

However, what is important for our analysis is not to show which model is best, or which model produces the best fit to the data, but rather to show that both models display similar spectral residuals.

\subsection{The JAIVEx and ancillary data}

The IASI spectra used in our analysis are daytime spectra measured during the 2007 JAIVEx campaign (see FAAM (2007) for more details) over the Gulf of Mexico. We have a series of 6 spectra for 29 April 2007, 16 spectra for 30 April 2007, and finally 3 spectra for 4 May 2007. The total of 25 soundings are well collocated with dropsonde observations. The spectra were recorded in clear sky conditions, selected on the basis of either high resolution satellite imagery from the Advanced Very High Resolution Radiometer (AVHRR) on MetOp and in-flight observations. The spectra for the 29 April 2007 were measured at nadir whereas the spectra for the 30 April 2007 and 4 May 2007 were measured at a viewing angle of 22.50 degrees.

Dropsonde and ECMWF model data, which have been used to have a best estimate of the atmospheric state during each MetOp overpass, have been prepared and made available to us by the JAIVEx team (FAAM, 2007). The

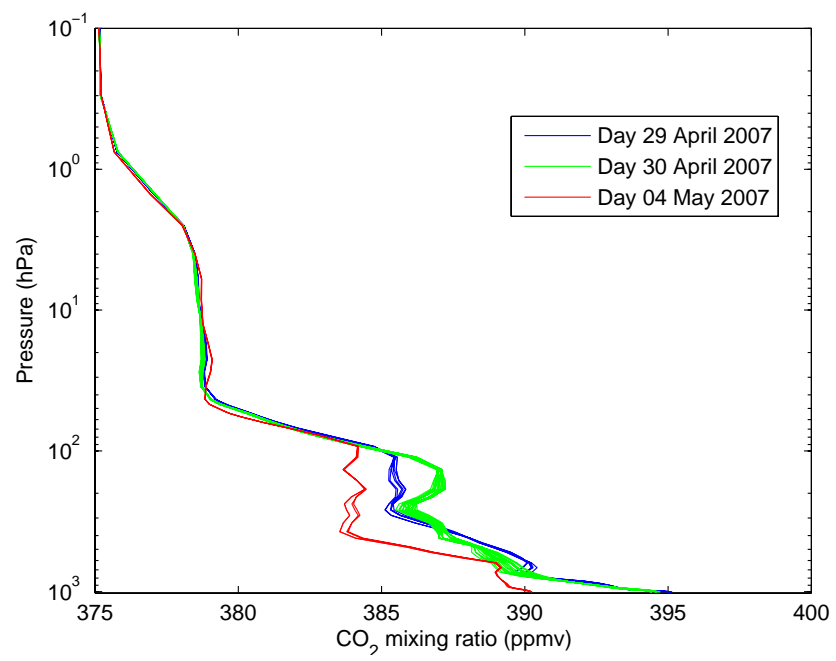

Fig. 6. The $\mathrm{CO}_{2}$ mixing ratio profiles derived from the ECMWF analysis and time-space co-located with the 25 JAIVEx IASI soundings.

JAIVex dataset contains dropsonde profiles of temperature, water vapour and ozone, which extend up to $400 \mathrm{hPa}$. Above $400 \mathrm{hPa}$ only ECMWF model data are available. The atmospheric state vectors used in this study use JAIVex dropsonde data up to $400 \mathrm{hPa}$ supplemented by collocated ECMWF forecasts of temperature, water vapour and ozone from $400 \mathrm{hPa}$ to $0.1 \mathrm{hPa}$ (corresponding to about $65 \mathrm{~km}$ ). For illustrative purposes, the ECMWF data merged with the dropsonde data are shown for one day in Fig. 5.

ECMWF $\mathrm{CO}_{2}$ profiles obtained from the assimilation of AIRS radiances were also used in this study. The $\mathrm{CO}_{2}$ vertical profiles were interpolated in space and time to the 25 IASI soundings. The $\mathrm{CO}_{2}$ vertical profiles are shown in Fig. 6 .

Our forward calculations require a further extrapolation of the state vector to $0.005 \mathrm{hPa}$ and the inclusion of vertical profiles of additional trace gases. These were set to climatological values using the compilation by Anderson et al. (1986). The same compilation was used to extrapolate the state vector to the top pressure level at $0.005 \mathrm{hPa}$.

It should be stressed that the correct specification of the additional trace gases is of little relevance for the spectral range 645 to $700 \mathrm{~cm}^{-1}$, which is dominated by $\mathrm{CO}_{2}$ absorption. Because this range is completely insensitive to the lower troposphere, the radiative transfer is completely governed by the temperature and $\mathrm{CO}_{2}$ mixing ratio profiles.

\section{Spectral residuals using the state vector from dropsonde and ECMWF forecasts}

Figure 7 shows the spectral residuals in the range 645 to $700 \mathrm{~cm}^{-1}$ for the $\sigma$-IASI and RTTOV models. These were obtained by computing synthetic IASI spectra using the forward model $F$ and the state vector $\hat{\boldsymbol{v}}$ which consists of 


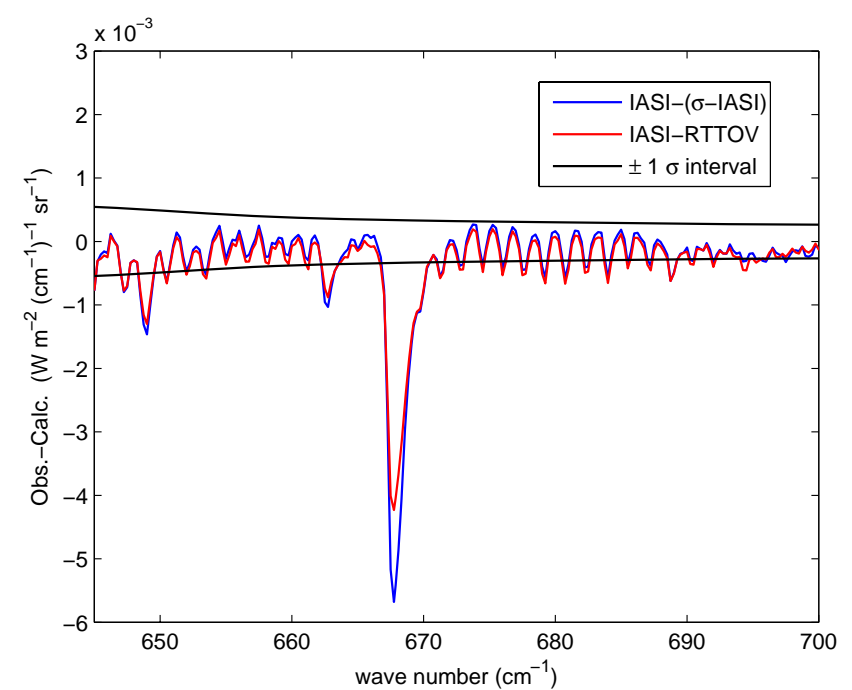

Fig. 7. Spectral residual averaged over the 25 IASI soundings. The input state vectors have been obtained by the dropsonde+ECMWF data. The residual has been computed based on the two forward models $\sigma$-IASI and RTTOV.

dropsonde observations extrapolated to the upper atmosphere using the ECMWF model data. In Fig. 7 the spectral residual has been averaged over the total of 25 IASI soundings. The $\pm 1 \sigma$ error bars are based on the IASI level $1 \mathrm{C}$ radiometric noise. The error bars apply to one single IASI spectrum and they are shown here as a reference against which to compare the magnitude of the residuals.

Figure 7 shows that the spectral residuals follow very closely the spectral signature of the $\mathrm{CO}_{2}$ lines. However, apart from the core of the $\mathrm{CO}_{2}$ Q-branch at $667 \mathrm{~cm}^{-1}$, where the residual exceeds the noise level by a factor of 10 and more, the difference between observed and calculated spectra is usually within the IASI radiometric noise.

The residuals are largely independent of the forward model. It can be seen that the two forward models agree very well. They display very similar patterns with large residuals at $667 \mathrm{~cm}^{-1}$.

Regarding the residuals at $667 \mathrm{~cm}^{-1}$, it can be seen that RTTOV exhibits a slightly lower bias, which means that RTTOV is slightly colder than $\sigma$-IASI at $667 \mathrm{~cm}^{-1}$. This result can be explained in terms of the different pressure grid and the interpolation process involved in the specification of the state vector on the RTTOV levels. In fact, because of the interpolation, the RTTOV-gridded temperature profile is colder than the $\sigma$-IASI-gridded profile around the stratopause level. This is exemplified in Fig. 8, which compares the temperature profile originally defined on the $\sigma$-IASI grid with the profile interpolated to the RTTOV grid.

The $667 \mathrm{~cm}^{-1} \mathrm{Q}$-branch is sensitive to temperature values that cover a wide range of altitudes. In Fig. 9 we show the temperature Jacobian for the spectral range 645 to $700 \mathrm{~cm}^{-1}$. It can be seen that the radiance (mostly evident at the cen-

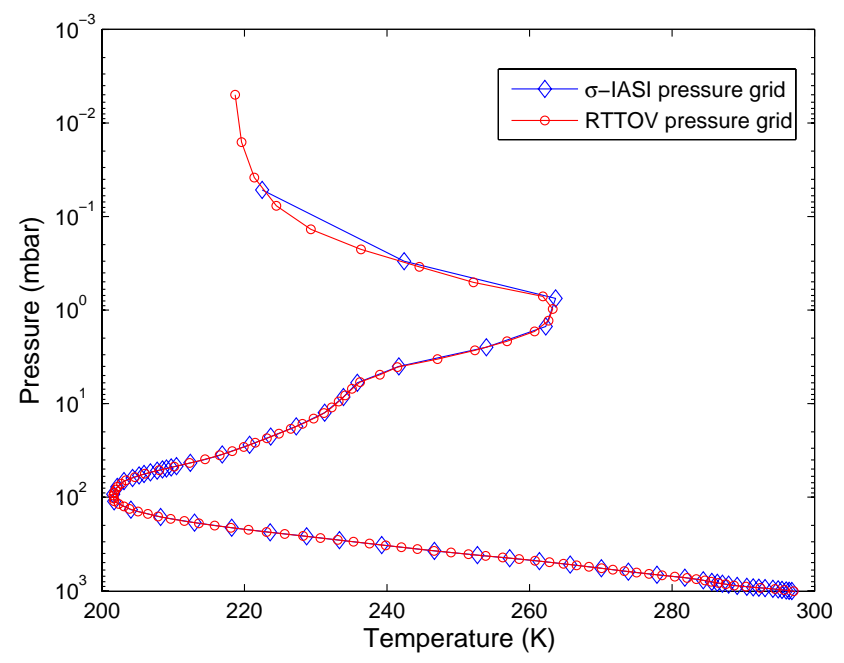

Fig. 8. The interpolation of the temperature profile from the $\sigma$-IASI grid to that of RTTOV. This example shows that the interpolation process yields a temperature profile which is slightly colder at the stratopause level.

tre of the Q-branch) is sensitive to changes in the temperature profile at altitudes between 10 and $1 \mathrm{hPa}$, an exceedingly wide range. If the radiance bias is attributable to temperature errors, this means that in order to produce the large residuals we see in Fig. 7, errors in the temperature profile are likely to be larger in between this range. It is also worth noting that Fig. 9 shows that the range 645 to $700 \mathrm{~cm}^{-1}$ has no sensitivity to tropospheric emission. Thus, all the emission in the range 645 to 700 is essentially due to $\mathrm{CO}_{2}$ alone.

\section{Quantifying the systematic error in the ECMWF forecasts of temperature}

The high quality of the IASI spectra (this includes the spectral range around the $\mathrm{CO}_{2}$ Q-branch at $667 \mathrm{~cm}^{-1}$ ) allows us to perform an in depth analysis to assess whether or not the large discrepancies at $667 \mathrm{~cm}^{-1}$ can be attributed to errors in the temperature profiles.

To this end we have performed the direct inversion of the 25 IASI spectra using the model $\delta$-IASI (Carissimo et al., 2005; Masiello et al., 2009). When performing the retrievals, the non-linear inverse problem is initialized with a state vector which is derived by Empirical Orthogonal Functions (EOF) regression (Masiello and Serio, 2004; Serio et al., 2009, 2008a). Thus, the final inverted state vector dependends only on the IASI spectral radiances and is totally independent of the ECMWF temperature.

The retrieval scheme performs the simultaneous inversion of the skin temperature, temperature, water vapour (mixing ratio) and ozone (mixing ratio) profiles. The spectral regions used in the inversion are shown in Fig. 10. It is important here to stress that we do not make use of the $\mathrm{CO}_{2} v_{3}$-band 


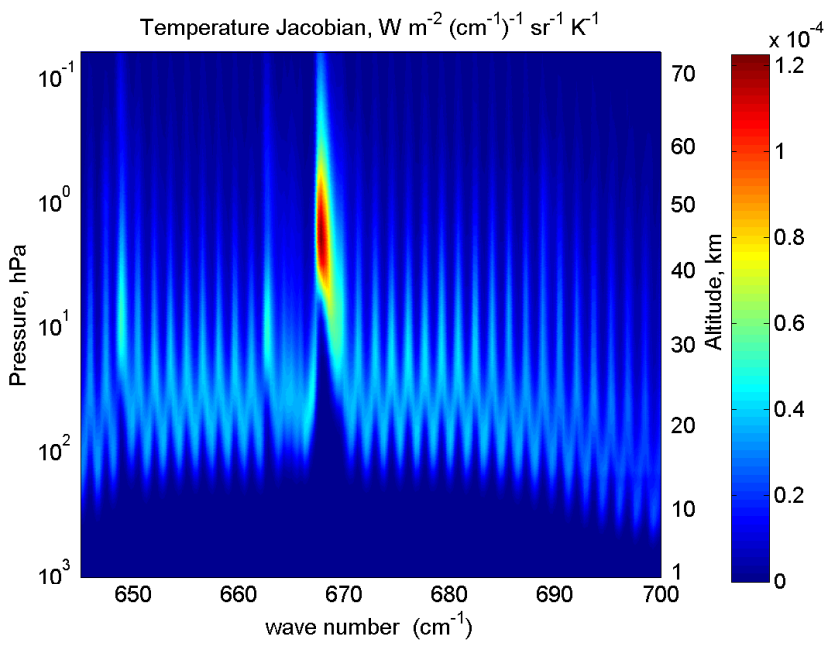

Fig. 9. An example of the radiance derivative (Jacobian) with respect to the temperature profile in the range 645 to $700 \mathrm{~cm}^{-1}$.

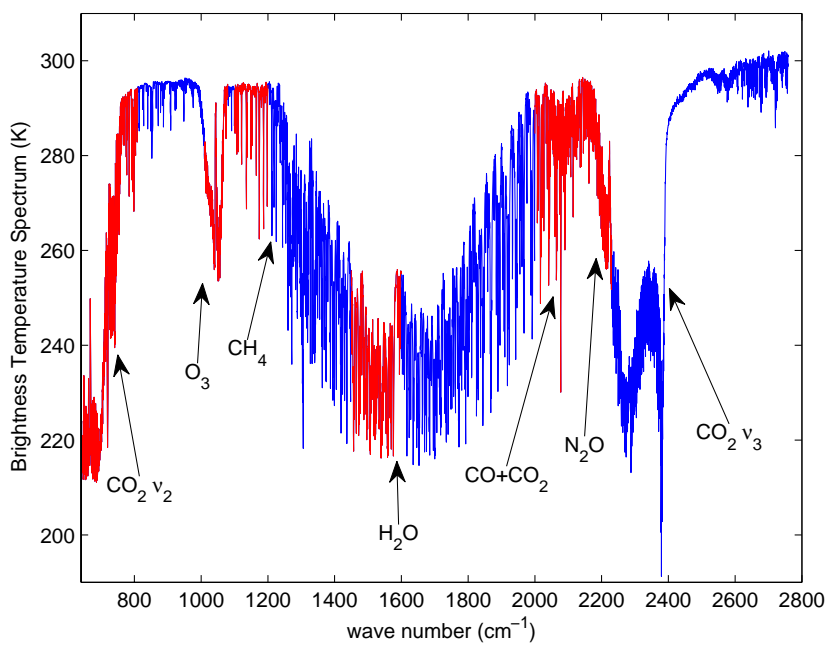

Fig. 10. The IASI spectral coverage and the spectral intervals (in red) used for the inversions of skin temperature, temperature, water vapour and ozone profiles.

(which ranges approximately from 2100 to $2400 \mathrm{~cm}^{-1}$ ) because of non-LTE effects. In fact, the 25 IASI soundings have been recorded during daytime.

As discussed in the previous sections, when performing the iterations that lead to the final retrieval, the $\delta$-IASI uses forward calculations performed by the direct model $\sigma$-IASI. For this reason, we expect a high degree of consistency between the residuals and the state vector obtained from a retrieval scheme that uses the same forward model. Therefore, we have made an independent assessment of our results by computing the RTTOV residuals (IASI-RTTOV) using the same inverted state vector, $\hat{\boldsymbol{v}}$, obtained from the $\delta$-IASI inversion.
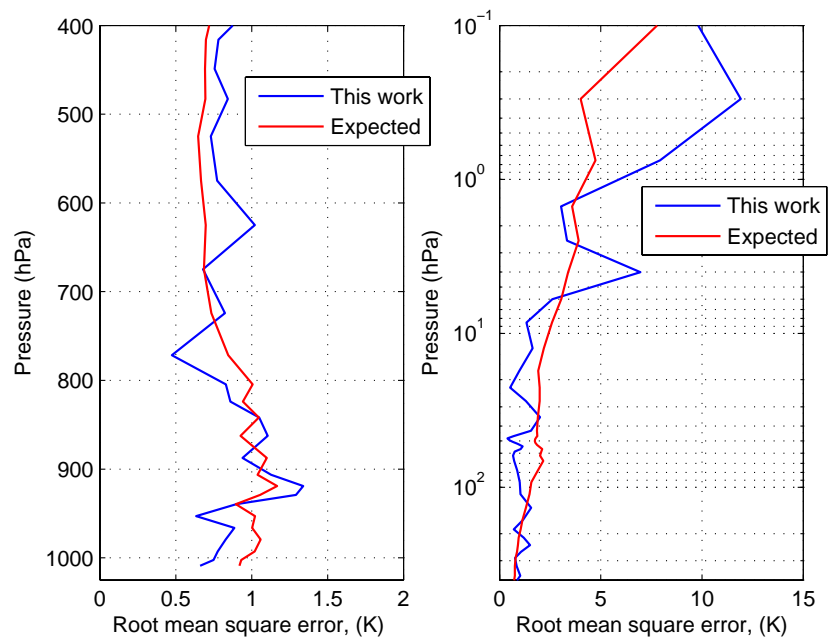

Fig. 11. The root mean square difference between retrieved and dropsonde/ECMWF temperature profiles (blue line). The figure also shows (red line) the root mean square error based on simulations. Panel (a) shows the altitude range where we have dropsonde observations, while panel (b) shows the altitude range where the temperature information is derived from the ECMWF short-term forecast fields.

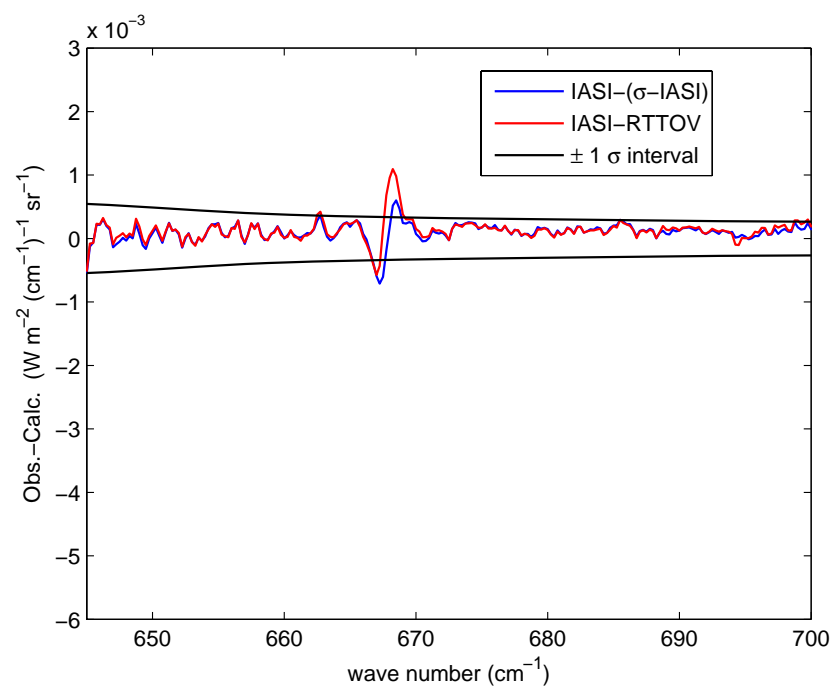

Fig. 12. Same as Fig. 7, but now the input state vectors have been obtained by direct inversion of IASI data.

Before moving to the analysis of the spectral residual, we briefly discuss the retrieval accuracy achieved by $\delta$-IASI. Figure 11 shows the root mean square of the difference between retrieved and dropsonde/ECMWF profiles. In the pressure range 1025 to $400 \mathrm{hPa}$, where we have information from co-located dropsondes, it can be seen that the errors are close to $1 \mathrm{~K}$ and they are comparable to the errors that are expected based on simulated retrieval exercises. Note that the root mean square difference is computed over 25 profiles, so 
that statistical fluctuations are still expected to play a significant role. Bearing this in mind, the good agreement between inversions and dropsonde provide some more confidence in the inverse scheme as far as its accuracy is concerned.

A good retrieval accuracy for temperature is also achieved in the range 400 to $10 \mathrm{hPa}$, where we have information from the ECMWF forecasts alone. In the range 10 to $1 \mathrm{hPa}$, apart from an isolated spike at $5 \mathrm{hPa}$, the retrieval accuracy is still good. However, in the range 1 to $0.1 \mathrm{hPa}$ we can see that the computed root mean square difference is far from the expected value, especially at the stratopause level.

Coming back to the spectral residuals, we now see that the use of the retrieved state vectors greatly improves the spectral residuals, which are now smoother and smaller in magnitude, as shown in Fig. 12. In this figure we have used the same scale used in Fig. 7 to allow the reader a more direct comparison.

It is quite evident that the difference at $667 \mathrm{~cm}^{-1}$ has been reduced by almost one order of magnitude. Furthermore, the wave-like pattern introduced in the residuals by the regular spacing of $\mathrm{CO}_{2}$ lines (which is clearly evident in Fig. 7) has almost disappeared. The two forward models used in this study yield very similar results. In fact, both models respond in the same way to the new input state vectors.

Based on these results and on the arguments presented in the previous sections, we suggest that the residuals observed around $667 \mathrm{~cm}^{-1}$ are most likely due to the inconsistency of the temperature profile in the upper stratosphere.

To estimate the errors of the ECMWF temperature profiles, we can compare the retrieved temperature profiles with those obtained from the dropsonde/ECMWF. Figure 13 shows that the two sets agree almost everywhere within $\approx \pm 1 \mathrm{~K}$ with the exception of the upper atmosphere, below 5-6 hPa, where the temperature difference can reach values as large as $12 \mathrm{~K}$.

Although these results only apply to the location of the soundings considered in this study, if we accept the conclusion that radiance errors are indeed related to temperature errors, then the global and consistent nature of the radiance bias at $667 \mathrm{~cm}^{-1}$ suggests that errors in the ECMWF forecasts of temperature at the stratopause are also distributed globally. However, it is fair to say that while the sign of the radiance bias is always negative, its magnitude is not a constant, which means that the magnitude of local temperature error is likely to differ from the values discussed above. An example of the global distribution of the radiance residuals is shown in Fig. 14 where we plot the difference between observations and calculations for IASI channel \#92, which is centered at $667.75 \mathrm{~cm}^{-1}$. The calculations have been performed with LBLRTM using fields of temperature, water vapour and ozone obtained from ECMWF short-range forecasts. The results shown in the map refer to one day of thinned IASI data (4 April 2008). It can be seen that the residuals (expressed in units of equivalent brightness temperature) are negative everywhere, with an average magnitude of around $-2 \mathrm{~K}$.

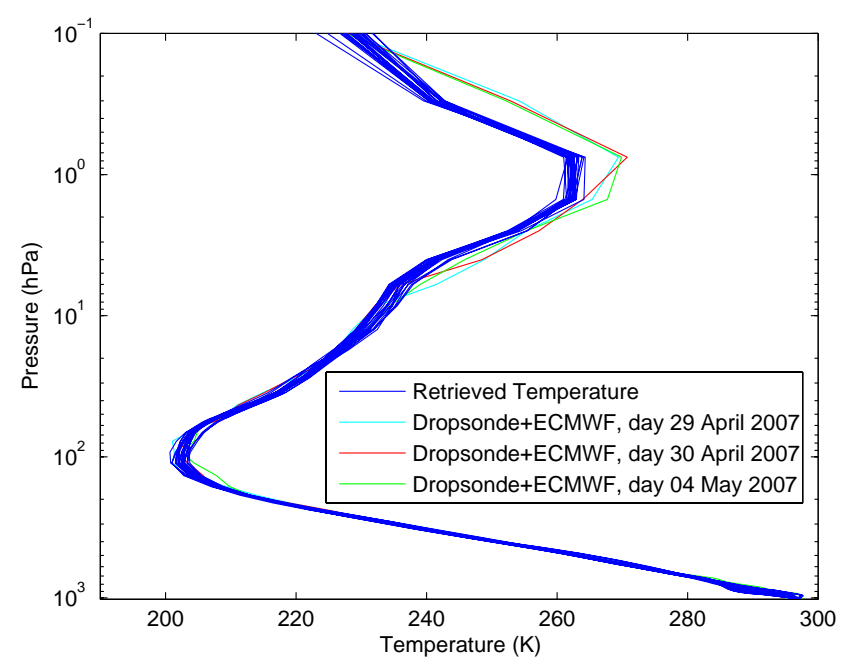

Fig. 13. The 25 IASI inverted temperature profiles compared to the observations (dropsonde/ECMWF). The dropsonde/ECMWF observations are averaged to form one single profile for each day, which is shown in the figure.

To conclude this section, we note that most of the radiance residuals discussed in the paper have been computed utilizing forecasts of temperature fields generated using the cycle 33R1 of the ECMWF Integrated Forecast System (IFS) which was operational until October 2008). At the time of writing, the operational version of the ECMWF model is 36R1. This version includes a number of upgrades which could in principle affect the quality of the temperature fields and potentially change the conclusions reached in the paper. Consequently, analogously to what has been done to produce the results shown in Fig. 1, we have computed radiance residuals for a period of two weeks during the month of April 2010 using the new ECMWF cycle. The April 2010 residuals at $667 \mathrm{~cm}^{-1}$ (not shown here) differ only very slightly from those obtained during April 2008 using the old ECMWF model. Then, according to what is argued in this paper, errors in the ECMWF analyis in the stratopause are still outstanding.

\subsection{Sensitivity to potential interfering factors}

\subsection{1 $\mathrm{CO}_{2}$ volume mixing ratio}

To understand better how the results of our inversions depend on the $\mathrm{CO}_{2}$ mixing ratio profile, we have performed a further retrieval exercise where the $\mathrm{CO}_{2}$ mixing ratio is assumed to be constant.

To this end we have assumed a constant mixing ratio of 385 ppmv. This is the global average value for April 2007 according to the NASA Earth System Monitoring Laboratory (Global Monitoring Division, e.g. see http://www.esrl.noaa. gov/gmd/ccgg/trends/). 

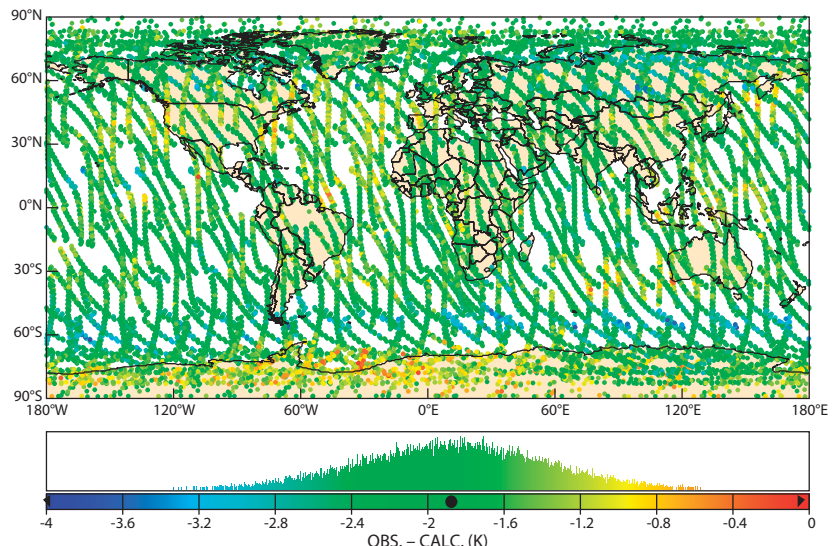

Fig. 14. Global distribution of the difference between observations and calculations for IASI channel $92\left(667.75 \mathrm{~cm}^{-1}\right)$ for one day $(4$ April 2008) of thinned IASI data. Results are expressed in units of equivalent brightness temperature $(\mathrm{K})$. Calculations have been performed using LBLRTM.
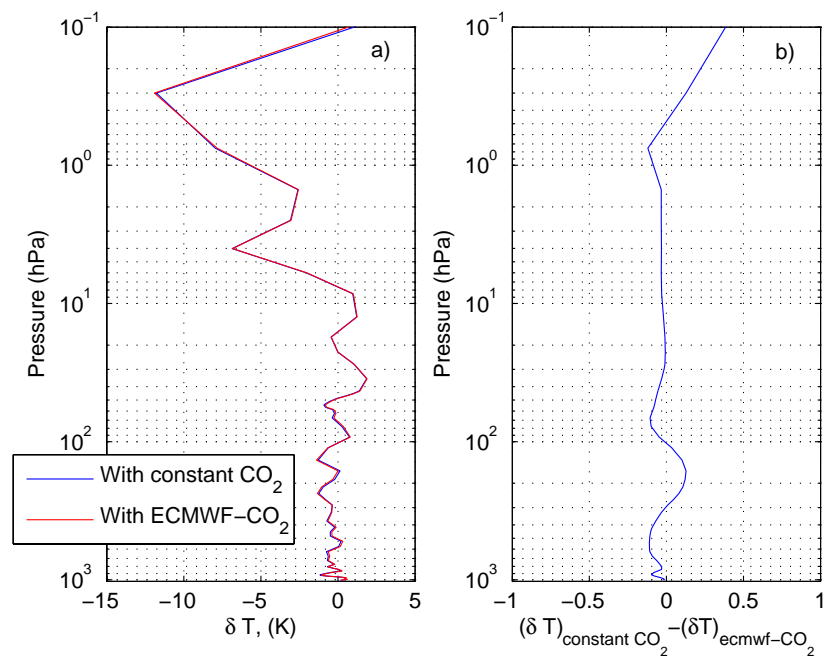

Fig. 15. Panel (a) shows the average difference (IASI retrievalECMWF) for temperature for the two inversion case studies: (1) constant mixing ratio for $\mathrm{CO}_{2}$ and (2) with the ECMWF-altitudedependent $\mathrm{CO}_{2}$ mixing ratio, respectively. Panel (b) gives the difference between the two curves shown in (a).

Figure 15 shows the average value of the difference between the retrieved and the ECMWF temperature profile, obtained for the cases where

1. the inverted profiles are obtained with the ECMWF$\mathrm{CO}_{2}$-mixing-ratio shown in Fig. 5 (hereafter this difference will be referred to as $\left.\delta T_{\text {ecmwf- }} \mathrm{CO}_{2}\right)$,

2. the inverted profiles are obtained with the constant mixing ratio for $\mathrm{CO}_{2}$ (hereafter this difference will be referred to as $\delta T_{\text {constant }-\mathrm{CO}_{2}}$ )
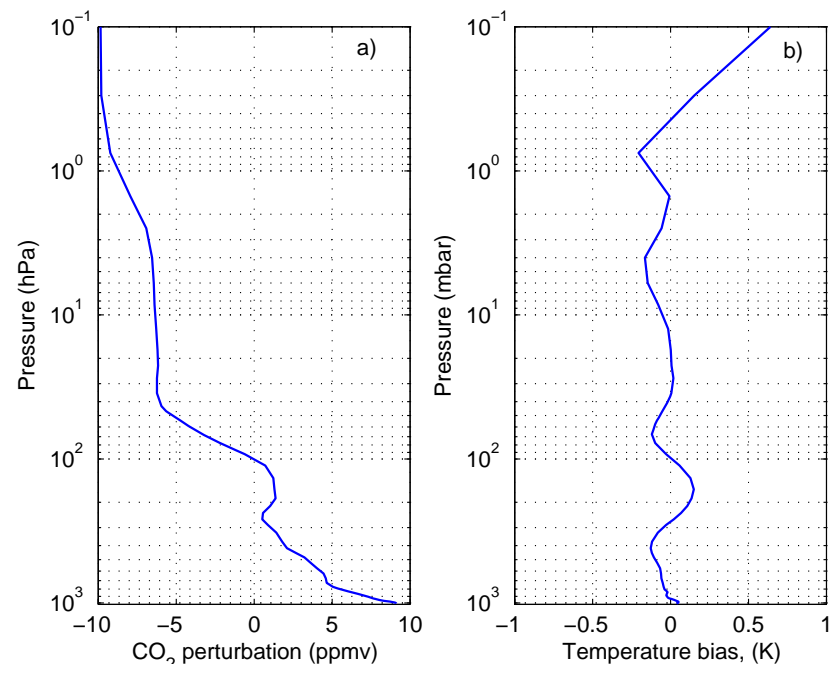

Fig. 16. The sensitivity of the retrieved temperature profile to a non correct specification of the $\mathrm{CO}_{2}$ mixing ratio profile. Panel (a)) shows the difference between the assumed $\mathrm{CO}_{2}$ profile and the true profile. Panel (b) shows how the differences shown in panel (a) would bias the inverted temperature profile.

From Fig. 15 it can be seen that the results are very similar. It is worth noting that when we consider the direct difference between the inverted profiles, that is $\delta T_{\text {constant }-\mathrm{CO}_{2}-}$ $\delta T_{\text {ecmwf }-\mathrm{CO}_{2}}$, the larger difference is attained in the upper atmosphere. However, this difference is smaller than $1 \mathrm{~K}$.

The results shown in Fig. 15b can also be interpreted as the bias that would affect the inverted profile if we overestimate the $\mathrm{CO}_{2}$ mixing ratio in the upper atmosphere.

This can be demonstrated using a direct sensitivity analysis where we compute the derivative of the temperature profile with respect to the mixing ratio profile of $\mathrm{CO}_{2}$. This analysis, which will be illustrated below, shows that the sensitivity to the $\mathrm{CO}_{2}$ perturbation is less than $1 \mathrm{~K}$, if we assume a variation of the $\mathrm{CO}_{2}$ mixing ratio profile of \pm 10 ppmv.

According to Carissimo et al. (2005), this derivative can be computed as

$$
\frac{\partial \hat{\boldsymbol{T}}}{\partial q}=\left(\mathbf{K S}^{-1} \mathbf{K}+\lambda \mathbf{B}^{-1}\right)^{-1} \mathbf{K S}^{-1} \mathbf{K}_{q}
$$

where $\hat{\boldsymbol{T}}$ is the estimated temperature profile vector, $q$ is the $\mathrm{CO}_{2}$ mixing ratio profile, $\mathbf{K}$ is the derivative matrix (or Jacobian) of the radiance with respect to the temperature profile, $\mathbf{K}_{q}$ the derivative of the radiance with respect to the $\mathrm{CO}_{2}$ mixing ratio profile, $\mathbf{B}$ is the background a-priori covariance matrix, $\mathbf{S}$ is the observational covariance matrix and $\lambda$ is an adaptive smoothing parameter, which is internally generated by $\delta$-IASI according to the so-called L-curve criterion (Hansen, 1992).

It is usually assumed that $\mathrm{CO}_{2}$ is well mixed in the atmosphere. However, there is strong evidence (Shia et al., 2006; 
Carlotti et al., 2007; Beagley et al., 2010) that this assumption leads to an overestimation of the $\mathrm{CO}_{2}$ mixing ratio in the stratosphere. Consequently, in this paper we analyze the effect of overestimating the $\mathrm{CO}_{2}$ profile in the stratosphere.

To this end, let us consider the case in which we perform the inversion for temperature assuming a constant value for the $\mathrm{CO}_{2}$ mixing ratio. Assuming that the $\mathrm{ECMWF} \mathrm{CO}_{2}$ mixing ratios (shown in Fig. 5) provide the correct profile, we have that the $\mathrm{CO}_{2}$ constant mixing ratio profile is in error by a quantity, $\delta q$, which, on average, can be estimated by

$\delta q=<q_{\mathrm{ecmwf}}>-\boldsymbol{q}_{o}$

where $\boldsymbol{q}_{o}$ is the constant mixing ratio vector, whose elements are all equal to $385 \mathrm{ppmv}$.

The bias, $\delta \boldsymbol{T}$, which results from having assumed a constant value for $\boldsymbol{q}$ is given by

$\delta \boldsymbol{T}=\frac{\partial \hat{\boldsymbol{T}}}{\partial q} \times \delta q$

For the case considered in this paper, this bias is shown in Fig. 16, where we see that although the largest value is to be expected in the upper part of the atmosphere, it is still smaller than $1 \mathrm{~K}$. It is also important to note that if we overestimate the $\mathrm{CO}_{2}$ mixing ratio (as we have done here), we obtain positive increments, which would reduce the differences between ECMWF and our retrieval.

Comparing Fig. 16b to Fig. 15b we see that the sensitivity analysis yields almost exactly the same results we have obtained by considering the difference between the inversion analysis performed assuming a variable and a constant $\mathrm{CO}_{2}$ mixing ratio. in passing, this result says that a variation of $\approx \pm 10$ ppmv along the $\mathrm{CO}_{2}$ profile can be dealt with a linear analysis.

The opposite situation, where the correct $\mathrm{CO}_{2}$ mixing ratio is assumed to be constant with altitude and we perform the inversion analysis with the ECMWF-altitude-dependent $\mathrm{CO}_{2}$ mixing ratio, would differ only in the sign of the bias since the analysis is linear.

However, irrespective of the sign, the magnitude of the temperature bias at the stratopause level resulting from a perturbation of the $\mathrm{CO}_{2}$ mixing ratio by $\pm 10 \mathrm{ppmv}$, is no greater than $\pm 1 \mathrm{~K}$, which is too small to explain the radiance bias in the $\mathrm{CO}_{2}$ Q-branch.

\subsubsection{Spectroscopic parameters: the $\mathrm{CO}_{2}$ continuum}

The accuracy of the currently available spectroscopic line parameters (line width, position and intensity) is difficult to assess. Based on the most recent data (e.g., HITRAN compilation (Rothman et al., 2005)) we do not expect that spectroscopic errors can result in the large bias shown in Fig. 7. Any effect due to random errors should be greatly reduced by the convolution of the monochromatic quantities with the
IASI Instrument Spectral Response Function, whereas the effect due to a systematic component should remain within the IASI error bars. Recent developments in the treatment of $\mathrm{CO}_{2}$ line mixing by Niro et al. (2004, 2005a,b) show that a comparison of model data with laboratory measurements, ground-based, ballon and airplane observations of solar and atmospheric emitted spectral radiance, does not support the hypothesis that the large discrepancies at $667 \mathrm{~cm}^{-1}$ are a result of spectroscopy alone. It is fair to say that these validations focus on the Q-branches at 617 and $720 \mathrm{~cm}^{-1}$. The longer paths involved in the study of the absorption in the Q-branch at $667 \mathrm{~cm}^{-1}$, mean the absorption in this region of the spectrum can be better and more effectively studied using space based observations. Nevertheless, state-ofthe-art spectroscopy suggests that, within the $15 \mu \mathrm{m}$ region, Q-branch lineshapes can be modeled with good accuracy (Strow and Reuter, 1988; Niro et al., 2004, 2005a,b).

However, the treatment of the $\mathrm{CO}_{2}$ continuum absorption is a potential source of uncertainty. In the present work, the $\mathrm{CO}_{2}$ absorption is modeled using the LBLRTM scheme (Shephard et al., 2009). According to this scheme, the $\mathrm{CO}_{2}$ absorption is split in two additive components, the line and continuum absorption. The behaviour in the far-wing of the line is described by the continuum component. In LBLRTM v. 11.6 (http://rtweb.aer.com/), the continuum absorption is modeled in terms of a spectral density function, $\tilde{f}(\sigma)$ which is independent of temperature and pressure. This function is shown in Fig. 17a where it can be seen that it exhibits a very narrow peak at the centre of the $667 \mathrm{~cm}^{-1} \mathrm{CO}_{2}$ Q-branch.

Because IASI radiances are colder than calculations in the centre of the band (see, e.g. Fig. 7), we might argue that we have an excess of continuum absorption around $667 \mathrm{~cm}^{-1}$.

To test this hypothesis, we have performed the computation of the sensitivity of the inverted temperature profiles to a perturbation of the $\mathrm{CO}_{2}$ continuum absorption using the same approach described in the previous section. The derivative of $\hat{\boldsymbol{T}}$ with respect to $\tilde{\boldsymbol{f}}$ (assumed here to be a function of the wave number $\sigma$ ) can be written as

$$
\frac{\partial \hat{\boldsymbol{T}}}{\partial \tilde{\boldsymbol{f}}}=\left(\mathbf{K S}^{-1} \mathbf{K}+\lambda \mathbf{B}^{-1}\right)^{-1} \mathbf{K} \mathbf{S}^{-1} \mathbf{K}_{f}
$$

where now $\mathbf{K}_{f}$ is the Jacobian with respect to the function $\tilde{\boldsymbol{f}}$. Note that since the spectral density function $\tilde{f}(\sigma)$ does not depend on the temperature profile, the derivative function can be easily integrated along the vertical, therefore the matrix $\mathbf{K}_{f}$ is a diagonal matrix, of size $N$ by $N$ where $N$ is the number of spectral radiances.

Also, note that the derivative matrix (7), is a $N_{L}$ by $N$ matrix, where $N_{L}$ is the number of atmospheric layers. For more details on the properties of the jacobian with respect to the continuum absorption see, e.g., Serio et al. (2008b). 

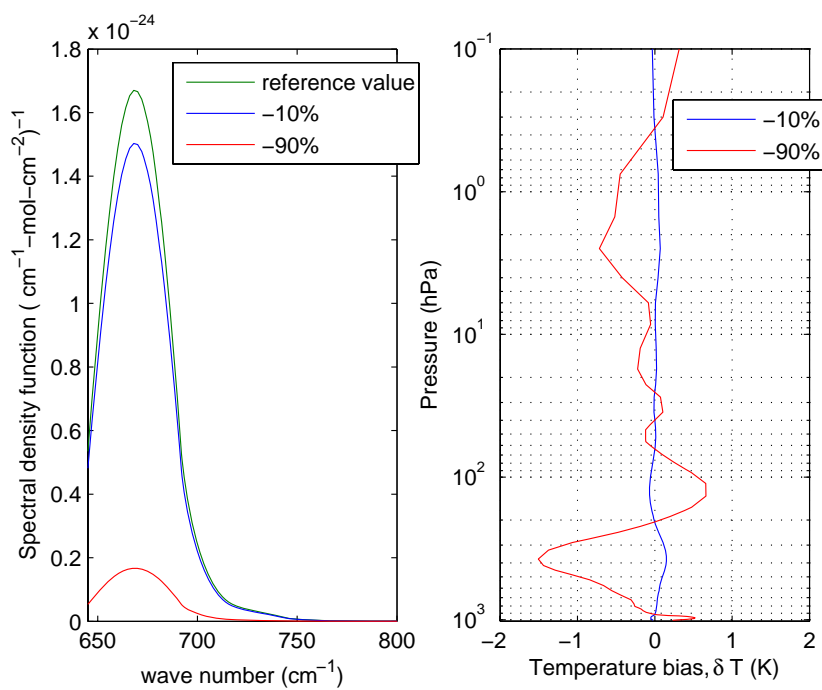

bias seen in Fig. 7 is the temperature profile. However, once we have adjusted for temperature we are left with the residual bias shown in Fig. 12, which is still too large and could well be a result of incorrect spectroscopy, presumably line positions.

\section{Conclusions}

We have performed a retrieval of the atmospheric state using IASI data during the month of April 2007. Large discrepancies have been observed between measured and simulated IASI radiances at the center of the fundamental $\mathrm{CO}_{2}$ Q-branch at $667 \mathrm{~cm}^{-1}$. For the soundings considered in this paper we provide compelling evidence that the origin of these discrepancies is attributable to errors in the ECMWF temperature fields at the stratopause level. The sign of the error in the temperature profiles is negative and its magnitude can reach up to $12 \mathrm{~K}$ and shows that IASI is actually sensing

Fig. 17. Sensitivity analysis to the $\mathrm{CO}_{2}$ continuum absorption. Panel (a) shows the spectral density function we have used as a reference (green curve) in our calculations along with the values of the same density function scaled down by $10 \% 90 \%$ respectively. Panel (b) shows the response in terms of temperature bias to a perturbation equal to the reference-scaled value.

If we vary the wave number dependent density function by the constant value $\delta \tilde{f}$ we should observe a bias in temperature, $\delta T$ given by

$\delta T=\frac{\partial \hat{T}}{\partial \tilde{f}} \times \delta \tilde{f}$

Figure $17 \mathrm{~b}$ shows the results for the case where we vary the continuum density function by $-10 \%$ and $-90 \%$ respectively. As it can be seen from Fig. 17b, the resulting temperature bias tends to be larger in the troposphere, and even in the case where the reference value is reduced by $90 \%$, the bias in the upper part of the atmosphere would still be smaller than $1 \mathrm{~K}$. It should be stressed that the behaviour in the troposphere is easily understood when we consider that the continuum absorption has is larger effect in the line-wings, which are mostly sensitive to the emission form the lower atmosphere.

Finally, another interesting aspect of our analysis is the large oscillation of the sign of the spectral radiance bias (see Fig. 12) around the center of the Q-branch at $667 \mathrm{~cm}^{-1}$. The change of the sign of the bias is likely to be modulated by the temperature inversion at the stratopause level. From Fig. 13 we see that the retrieved profiles at the stratopause level are almost isothermal, before the lapse rate becomes negative. The $\mathrm{CO}_{2}$ absorption coefficient, $k(\sigma)$ has a marked change when passing through the band centre at $667 \mathrm{~cm}^{-1}$ (Strow and Reuter, 1988). In case now we assume that the retrieved profiles are correct, what we see is a supposedly non correct behaviour of $k(\sigma)$ modulated by the the temperature profile shape. In conclusion, we can say that the main driver of the a colder upper stratosphere and lower mesosphere than that represented by the ECMWF model.

We have shown that it is very unlikely that the radiance bias can be attributed to the forward radiative transfer model. Two different forward models, using different pressure grids and methodological approaches, yield consistent spectral residuals.

Since the radiance bias does not show any day/nigth variability, we can rule out the possibility that non-LTE effects might be responsible for it.

Because of the spectrally localized nature of the radiance bias, it is unlikely that the bias is a result of random errors in the spectroscopic line parameters. The convolution at the IASI spectral resolution of the monochromatic transmittances would almost reduce to zero any effect due to this source of error.

We have identified and investigated three alternative potential sources of error, which could explain the radiance bias. These sources are

- the temperature profile in the upper part of the atmosphere;

- the $\mathrm{CO}_{2}$ mixing ratio variability with altitude;

- the $\mathrm{CO}_{2}$ continuum absorption.

We found that even if we change the $\mathrm{CO}_{2}$ continuum absorption by $\pm 90 \%$, this would affect the retrieved temperature profile by an amount not greater than $\pm 0.5 \mathrm{~K}$. An overestimation by $10 \mathrm{ppmv}$ of the $\mathrm{CO}_{2}$ mixing ratio in the upper part of the atmosphere would result in a very similar temperature bias. In the latter case, the bias would be positive and therefore it would tend to compensate rather than accentuate the negative bias observed in the IASI radiances. Therefore, the most likely source of the radiance bias is errors in the temperature profile. 
Although the temperature profile is the primary source of the observed bias, it is not the only source. In fact, the radiance residuals computed using the retrieved atmospheric state show that the bias at the center of the $667 \mathrm{~cm}^{-1} \mathrm{Q}$ branch is still different from zero, which suggests the presence of some sort of systematic errors (probably due to the incorrect specification of line positions). The study of the residual bias deserves more research efforts and should be analyzed with the help of independent temperature profile data. In this respect, the synergetic use of MIPAS and IASI could be highly beneficial to check for the consistency of the spectroscopy at $667 \mathrm{~cm}^{-1}$ and we hope that our paper can stimulate more research work along this line.

To conclude, we have shown that the use of radiances at the centre of the strong $667 \mathrm{~cm}^{-1} \mathrm{Q}$-branch of $\mathrm{CO}_{2}$ offers a formidable tool for the remote sensing of the temperature in the upper stratosphere. Since the use of radiances in this spectral region allows us to probe the atmospheric temperatures for a wide range of altitudes between 30 and $65 \mathrm{~km}$, the fundamental $\mathrm{CO}_{2}$ Q-branch at $667 \mathrm{~cm}^{-1}$ could be used to study, e.g., long-term warming or cooling tendencies of the upper stratosphere. As Fig. 2 suggests, such kind of study could be performed by the re-analysis of IMG data.

Acknowledgements. IASI has been developed and built under the responsibility of the Centre National d'Etudes Spatiales (CNES, France). It is flown onboard the Metop satellites as part of the EUMETSAT Polar System. The IASI L1 data are received through the EUMETCast near real time data distribution service. We thank Dr Stuart Newman (Met Office) for providing the JAIVEx data. The JAIVEx project has been partially funded under EUMETSAT contract Eum/CO/06/1596/PS. The FAAM BAe 146 is jointly funded by the Met Office and the Natural Environment Research Council. The US JAIVEx team was sponsored by the National Polar-orbiting Operational Environmental Satellite System (NPOESS) Integrated Program Office (IPO) and NASA.

Edited by: A. Richter

\section{References}

Amato, U., Masiello, G., Serio C., and Viggiano, M.: The $\sigma$-IASI code for the calculation of infrared atmospheric radiance and its derivatives, Environ. Model. Softw., 17(7), 651-667, 2002.

Anderson, G. P., Clough, S. A., Kneizys, F. X., Chetwind, J. H., and Shettle, E. P.: AFGL Atmospheric concentration profiles (0$120 \mathrm{~km}$ ), AFGL (OPI), Hanscom AFB, MA 01736, USA, Rep. AFGL-TR-86-0110, 1986.

Beagley, S. R., Boone, C. D., Fomichev, V.I., Jin, J. J., Semeniuk, K., McConnell, J. C., and Bernath. P. F.: Atmospheric Chemistry and Physics First multi-year occultation observations of $\mathrm{CO}_{2}$ in the MLT by ACE satellite: observations and analysis using the extended CMAM, Atmos. Chem. Phys., 10, 1133-1153, doi:10.5194/acp-10-1133-2010, 2010.

Carissimo, A., De Feis, I., and Serio, C., The physical retrieval methodology for IASI: the $\delta$-IASI code, Environ. Model. Softw., 20, 1111-1126, 2005.
Carlotti, M., Dinelli, B. M., Niro, F., and Papandrea, E.: Stratospheric Distribution of $\mathrm{CO}_{2}$ from the MIPAS High-Resolution full Mission, in: Proceedings Envisat Symposium 2007, Montreux, Switzerland, 23-27 April 2007, ESA SP-636, 2007.

DeSouza-Machado, S., Strow, L. L., Tobin, D., Motteler, H., and Hannon, S. E.: kCARTA: an atmospheric radiative transfer algorithm using compressed lookup tables. Univ. Maryland Baltimore County, Dept. Physics, Tech. Report, online available at: http:/asl.umbc.edu/pub/rta/kcarta, 2002.

Collard, A. D. and McNally, A. P.: The assimilation of Infrared Atmospheric Sounding Interferometer radiances at ECMWF, Q. J. Roy. Meteorol. Soc. 135, 1044-1058, 2009.

Engelen, R. J, Serrar, S., and Chevallier, F.: Four dimensional data assimilation of Atmospheric $\mathrm{CO}_{2}$ using AIRS observations, J. Geophys. Res., 114, D03303, doi:10.1029/2008JD010739, 2009.

FAAM, UK Meteorological Office (Taylor, J.), FAAM - Joint Airborne IASI Validation Experiment (JAIVEX). British Atmospheric Data Centre, 2007, available online at: http://badc.nerc. ac.uk/data/jaivex/, last access: 30 December 2010.

Fischer, H., Birk, M., Blom, C., Carli, B., Carlotti, M., von Clarmann, T., Delbouille, L., Dudhia, A., Ehhalt, D., Endemann, M., Flaud, J. M., Gessner, R, Kleinert, A., Koopman, R., Langen, J., Lopez-Puertas, M., Mosner, P., Nett,H., Oelhaf, H., Perron, G., Remedios, J., Ridolfi, M., Stiller, G., and Zander, R.: MIPAS: an instrument for atmospheric and climate research, Atmos. Chem. Phys., 8, 2151-2188, doi:10.5194/acp-8-2151-2008, 2008.

Kobayashi, H., Shimota, A., Yoshigahara, C., Yoshida, I., Uehara, Y., Kondo, K.: Satellite-borne high-resolution FTIR for lower atmosphere sounding and its evaluation. IEEE Trans. Geosci. Remote Sens., 37, 1496-1507, 1999.

Grieco, G., Masiello, G., Matricardi, M., Serio C., Summa D., and Cuomo V.: Demonstration and validation of the $\varphi$-IASI inversion scheme with NAST-I data, Q. J. Roy. Meteorol. Soc., 133(S3), 217-232, 2007.

Hansen, C.: Analysis of discrete ill-posed problems by means of the L-curve, SIAM Review, 34, 561-580, 1992.

Illingworth, S. M., Remedios, J. J. and Parker, R. J.: Intercomparison of integrated IASI and AATSR calibrated radiances at $11 \mu \mathrm{m}$ and $12 \mu \mathrm{m}$, IASI data Atmos. Chem. Phys., 9, 6677-6683, doi:10.5194/acp-9-6677-2009, 2009.

Masiello, G. and Serio, C.: Dimensionality-reduction approach to the thermal radiative transfer equation inverse problem, Geophys. Res. Lett., 31, L11105, doi:10.1029/2004GL019845, 2004.

Masiello, G., Serio, C., and Shimoda, H.: Qualifying IMG Tropical Spectra for Clear Sky, J. Quant. Spectrosc. Ra., 77/2, 131-148, 2003.

Masiello, G., Serio, C., Carissimo, A., Grieco G.: Application of $\phi$-IASI to IASI: retrieval products evaluation and radiative transfer consistency, Atmos. Chem. Phys., 9, 8771-8783, doi:10.5194/acp-9-8771-2009, 2009.

Matricardi, M.: An assessment of the accuracy of the RTTOV fast radiative transfer model using IASI data. Atmos. Chem. Phys., 9, 6899-6913, doi:10.5194/acp-9-6899-2009, 2009.

Matricardi, M.: A principal component based version of the RTTOV fast radiative transfer model, Q. J. Roy. Meteorol. Soc., 136, 1823-1835, 2010.

Matricardi, M., Chevallier, F., Kelly, K. and Thepaut, J.-N.: An improved general fast radiative transfer model for the assimilation of radiance observations, Q. J. Roy. Meteorol. Soc., 130, 153- 
173, 2004.

Niro, F., Boulet, C., and Hartmann, J.-M.: Spectra calculations in central and wing regions of $\mathrm{CO}_{2}$ IR bands between 10 and $20 \mu \mathrm{m}$. I: model and laboratory measurements, J. Quant. Spectrosc. Rad., 88, 483-498, 2004.

Niro, F., Hase, F., Camy-Peyret, C., Payan, S., and Hartmann, J.M.: Spectra calculations in central and wing regions of $\mathrm{CO}_{2} \mathrm{IR}$ bands between 10 and $20 \mu \mathrm{m}$. II. Atmospheric solar occultation spectra, J. Quant. Spectrosc. Ra., 90, 43-59, 200a5.

Niro, F., von Clarmann, T., Jucks, K., and Hartmann, J.-M.: Spectra calculations in central and wing regions of $\mathrm{CO}_{2}$ IR bands between 10 and $20 \mu \mathrm{m}$. III: atmospheric emission spectra, J. Quant. Spectrosc. Rad., 90, 61-76, 2005b.

Richter, A. and Wagner, T.: The IASI instrument onboard the METOP satellite: first results, edited by: Richter, A. and Wagner, T., Atmos. Chem. Phys.-Special Issue, 2009.

Ridolfi, M., Blum, U., Carli, B., Catoire, V., Ceccherini, S., Claude, H., De Clercq, C., Fricke, K. H., Friedl-Vallon, F., Iarlori, M., Keckhut, P., Kerridge, B., Lambert, J.-C., Meijer, Y. J., Mona, L., Oelhaf, H., Pappalardo, G., Pirre, M., Rizi, V., Robert, C., Swart, D., von Clarmann, T., Waterfall, A., and Wetzel, G.: Geophysical validation of temperature retrieved by the ESA processor from MIPAS/ENVISAT atmospheric limb-emission measurements, Atmos. Chem. Phys., 7, 4459-4487, doi:10.5194/acp-74459-2007, 2007

Rothman, L. S., Jacquemart, D., Barbe, A., Benner, D. C., Birk, M., Brown, L. R., Carleer, M. R., Chackerian, C., Chance, K., Coudert, L. H., Dana, V., Devi, V. M., Flaud, J. M., Gamache, R. R., Goldman, A., Hartmann, J. M., Jucks, K. W., Maki, A. G., Mandin, J. Y., Massie, S. T., Orphal, J., Perrin, A., Rinsland, C. P., Smith, M. A. H., Tennyson, J., Tolchenov, R. N., Toth, R. A., Vander Auwera, J., Varanasi, P. and Wagner, G.: The HITRAN 2004 molecular spectroscopic database, J. Quant. Spectrosc. Rad., 96, 139-204, doi:10.1016/j.jqsrt.2004.10.008, 2005.

Serio, C., Esposito, F., Masiello, G., Pavese, G., Calvello, M. R., Grieco, G., Cuomo, V., Buijs, H. L., and Roy, C. B.: Interferometer for ground-based observations of emitted spectral radiance from the troposphere: evaluation and retrieval performance, Appl. Opt., 47(21), 3909-3919, 2008a.
Serio, C., Masiello, G., Esposito, F., Di Girolamo, P., Di Iorio T., Palchetti, L., Bianchini, G., Muscari, G., Pavese, G., Rizzi, R., Carli, B., and Cuomo, V., Retrieval of foreign-broadened water vapor continuum coefficients from emitted spectral radiance in the $\mathrm{H}_{2} \mathrm{O}$ rotational band from 240 to $590 \mathrm{~cm}^{-1}$, Optics Express, 16(20), 15816-15833, 2008b.

Serio, C., Masiello, G., and Grieco, C.: EOF regression analytical model with applications to the retrieval of atmospheric temperature and gas constituents concentration from high spectral resolution infrared observations, in: Environmental Modelling: New Research, edited by: Findley, P. N., Nova Science Publishers, Inc., USA, 51-88, 2009.

Shephard, M. W., Clough, S. A., Payne, V. H., Smith, W. L., Kireev, S., and Cady-Pereira, K. E.: Performance of the line-by-line radiative transfer model (LBLRTM) for temperature and species retrievals: IASI case studies from JAIVEx, Atmos. Chem. Phys., 9, 7397-7417, doi:10.5194/acp-9-7397-2009, 2009

Shia, R.-L., Liang, M.-C., Miller, C. E., and Yung, Y. L., $\mathrm{CO}_{2}$ in the upper troposphere: Influence of stratospheretroposphere exchange. Geophys. Res. Lett., 33, L14814, doi:10.1029/2006GL026141, 2006.

Strow, L. and Reuter, D.: Effect of line mixing on atmospheric brightness temperatures near $15 \mu \mathrm{m}$, Appl. Opt. 27(5), 872-878, 1988.

Strow, L., Hannon, S., and Tobin, D., in: Proceedings of the Conference on Characterization and Radiometric Calibration for Remote Sensing (CALCON). Logan, UT, Space Dynamics Laboratory of Utah State University, CD-ROM 1, 2008.

von Engeln, A., Healy, S., Marquardt, C., Andres, Y., and Sancho, F.: Validation of operational GRAS Radio Occultation Data Geophys. Res. Lett., 36, L17809, doi:10.1029/2009GL039968, 2009. 